http://jmscr.igmpublication.org/home/ ISSN (e)-2347-176x ISSN (p) 2455-0450

crossref DOI: https://dx.doi.org/10.18535/jmscr/v8i2.124

\title{
A Serological study on Leptospirosis during post flood epidemic in Kerala
}

\author{
Authors \\ Dr Neethu John ${ }^{1}$, Dr Tanya Tonny Mampilly, Dr Chris Mary Antony, \\ Dr Keerthy Bose, Dr Kiran.T Jose, Dr Ria Catherine Vincent, Dr J. Lancy* \\ ${ }^{1}$ Assistant Professor, GMC, Ernakulam \\ *Corresponding Author \\ Dr J.Lancy \\ Professor, GMC, Ernakulam, India
}

\begin{abstract}
Leptospirosis is an emerging and reemerging bacterial zoonosis caused by Spirochaetes belonging to the genus Leptospira. Various serological tests are available for the confirmatory diagnosis of Leptospirosis in the laboratory. IgM ELISA is commonly done in the first week of fever in most of the laboratories.PCR has been a major advance but it is available only in a few centres in Kerala. We had an epidemic in the first week of September 2018 following the floods. A total number of 373 blood samples collected from suspected cases of Leptospirosis were subjected to serological tests in the 24 hour Serology laboratory at Government Medical college Hospital, Ernakulam. IgM ELISA for Leptospira was found to be positive in 27 cases (7.2\%).Blood samples and urine samples were sent to NIV Alappuzha for PCR testing. Among the 111 serum and urine samples tested, 9 serum samples and urine sample were positive for Leptospira by PCR. Mortality rate was less than $1 \%$ in suspected cases and $11.11 \%$ in PCR positive cases of Leptospirosis.

Keywords: Leptospirosis, ELISA, PCR.
\end{abstract}

\section{Introduction}

Leptospirosis is an acute febrile illness, the severity of which varies from mild to rapidly fatal. Prompt and timely diagnosis is essential since antibiotic prophylaxis and therapy provides greatest benefits and significantly reduces the mortality rate when administered early in the course of the disease. Climatic and environmental factors were responsible for epidemics seen in Kerala in the recent years.

Nowadays various diagnostic tests like ELISA, MAT, IHA are available. Besides these diagnostic approaches, PCR provides accurate molecular based detection of Leptospira during the first few days of acute febrile illness before the development of anti-Leptospira antibodies.

\section{Materials and Methods}

Study Design: Cross sectional study

Study Setting: Department of Microbiology and Medicine, GMC, Ernakulam

Study Period: Post flood epidemic phase (September 2018)

Study Population: Suspected cases of Leptospirosis

Study Group (Age group): a1 year to 70 years Collection of Samples

From adult patients attending Medicine OPD with acute febrile illness, $5 \mathrm{ml}$ of blood was collected 
from anterior cubital vein by venipuncture under sterile precautions in vacutainers (plain) for serological tests. Another $5 \mathrm{ml}$ of blood was collected in EDTA vacutainers for PCR testing. Adult patients were advised to collect mid stream urine samples also in plastic screw capped wide mouthed sterile containers (SV30).Approximately $10 \mathrm{ml}$ of sample was collected.

From pediatric cases 2 samples, $2 \mathrm{ml}$ of blood each were collected under aseptic technique. One sample for serological tests (in plain vacutainer) and another one for PCR testing (collected in EDTA vacutainer). Urine sample (3-5ml) obtained from a few cases.

The samples were sent to the 24 hour Serology lab under department of Microbiology immediately after collection. The sample collected in the plain vacutainer was centrifuged and the serum was separated and IgM ELISA for Leptospira was done with the serum sample. The sample collected in the EDTA vacutainer was sent to NIV Alappuzha after perfect packing and labelling in an ice box.

\section{Results}

A total of 373 blood samples were collected from clinically suspected cases of Leptospirosis from Ernakulam district during the immediate post flood period in September 2018. All the samples were subjected to IgM ELISA. Out of the 373 samples tested, 27 samples were positive (7.2\%). During the initial stage, 111 samples were sent to National Institute of Virology (Kerala unit)at Alappuzha for PCR testing. (9 samples were positive $(8.1 \%)$.Among the IgM ELISA positive cases, $23(85 \%)$ were males and 4 patients $(15 \%)$ were females. Age wise distribution points out that 13 cases $(48 \%)$ were in the age group between 20 and 40

Analysis of samples collected from suspected cases of Leptospirosis

\begin{tabular}{|l|c|c|c|c|}
\hline $\begin{array}{l}\text { Total No. } \\
\text { of cases }\end{array}$ & \multicolumn{2}{|c|}{$\begin{array}{c}\text { IgM ELISA } \\
\text { Positive }\end{array}$} & \multicolumn{2}{c|}{$\begin{array}{c}\text { IgM ELISA } \\
\text { Negative }\end{array}$} \\
\hline & No. & $\%$ & No. & $\%$ \\
\hline 373 & 27 & 7.2 & 346 & 92.8 \\
\hline
\end{tabular}

Analysis of samples subjected to PCR

\begin{tabular}{|l|c|c|c|c|}
\hline $\begin{array}{l}\text { Total No. } \\
\text { of samples }\end{array}$ & \multicolumn{2}{|c|}{ PCR Positive } & \multicolumn{2}{c|}{ PCR Negative } \\
\hline & No. & $\%$ & No. & $\%$ \\
\hline 111 & 9 & 8.1 & 102 & 91.9 \\
\hline
\end{tabular}

Age wise distribution of suspected cases

\begin{tabular}{|l|c|c|}
\hline Age group & No. & $\%$ \\
\hline $0-10$ & 51 & 13.7 \\
\hline $11-20$ & 55 & 14.7 \\
\hline $21-30$ & 85 & 22.8 \\
\hline $31-40$ & 56 & 15 \\
\hline $41-50$ & 53 & 14.2 \\
\hline $51-60$ & 38 & 10.18 \\
\hline $61-70$ & 23 & 6.16 \\
\hline $71-80$ & 11 & 2.9 \\
\hline $81-90$ & 1 & 0.2 \\
\hline Total & 373 & 100 \\
\hline
\end{tabular}

Gender distribution -PCR samples

\begin{tabular}{|c|c|c|c|c|}
\hline \multicolumn{2}{|c|}{ Male } & \multicolumn{2}{c|}{ Female } & Total \\
\hline No. & $\%$ & No. & $\%$ & \\
\hline 82 & 73.8 & 29 & 26.13 & 111 \\
\hline
\end{tabular}

Analysis of IgM ELISA positive cases

Age wise distribution

\begin{tabular}{|l|c|c|}
\hline Age group & No. & $\%$ \\
\hline $0-10$ & 2 & 7.4 \\
\hline $11-20$ & 3 & 11.1 \\
\hline $21-30$ & 5 & 18.5 \\
\hline $31-40$ & 8 & 29.6 \\
\hline $41-50$ & 3 & 11.1 \\
\hline $51-60$ & 4 & 14.8 \\
\hline $61-70$ & 2 & 7.4 \\
\hline Total & 27 & \\
\hline
\end{tabular}

\section{Gender Distribution}

\begin{tabular}{|c|c|c|c|c|}
\hline \multicolumn{2}{|c|}{ Male } & \multicolumn{2}{c|}{ Female } & Total \\
\hline No. & $\%$ & No. & $\%$ & \\
\hline 23 & 85.1 & 4 & 14.8 & 27 \\
\hline
\end{tabular}

\section{IgM ELISA vs PCR}

\begin{tabular}{|c|c|c|c|c|}
\hline IgM & PCR & ELISA & ELISA & ELISA \\
ELISA & positive & positive & Negative & positive \\
positive & Total & PCR & PCR & PCR \\
Total No. & No. & negative & positive & positive \\
\hline 27 & 9 & 18 & 4 & 5 \\
\hline
\end{tabular}

IgM ELISA was positive (85.1\%) among males. IgM ELISA as well as PCR was positive in 5 cases $(4.5 \%)$.

\section{Discussion}

In our study, the preponderance of male patients in the age group between 20 and 40 denotes that 
Leptospirosis is common among men who are the working population exposed to the organism. Since males are more involved in outdoor activities they are at higher risk than females of acquiring the infection. Most of the studies have shown male preponderance. In contrast, a study from North India in sub Himalayan region by Chauhan et al in 2010 reported female preponderance of $77 \%$. In their study, out of the 13 confirmed cases of Leptospirosis, 10 were females $(76.92 \%)$ and 3 were males $(24 \%)$.

All the clinically suspected cases were having fever and myalgia (100\%).80\% of cases had headache and only $7 \%$ of the cases had jaundice. Same finding was observed in the previous studies conducted at Vellore, Puducherry and Calicut, Kerala and in North India.

Rainfall and exposure were defined as an important correlation in patients diagnosed with Leptospirosis. Following heavy rainfall, there will be dissemination of the disease in the urban zone.

The laboratory diagnosis of Leptospirosis is based on serological tests such as MAT (Macroscopic agglutination Test) and ELISA for detection of IgM antibodies.MAT is still the cornerstone of Leptospirosos diagnosis in spite of its disadvantages. IgM ELISA has been employed as a useful alternative. It is a reliable test and when used in combination with MAT gives good results in diagnosis. PCR is an important tool for early diagnosis of Leptospirosis cases. PCR positivity peaked from the $4^{\text {th }}$ day to $8^{\text {th }}$ day after onset of symptoms. In early phase of the disease, the sensitivity of PCR is $71 \%$ as reported by Summaiya et al from Gujarat in 2016.The detection rate by IgM ELISA was $59 \%$ in their study. In the present study, the sensitivity rate of PCR was $80 \%$ and IgM ELISA was $72 \%$. Fonseca et al showed that sensitivity increases to $96.5 \%$ in IgM ELISA and $93.1 \%$ in MAT along with PCR. Currently molecular based detection methods have been adopted by most of the reference laboratories because their sensitivity is more than other diagnostic tests available and they can detect very low levels of Leptospires in blood in acute phase of illness.

Leptospirosis has been reported to be endemic in several parts of South India including the state of Kerala with a seropositivity rate of $25.6 \%$. The seroprevalence rate during the post flood season was found to be $7.2 \%$.It may be due to the mixing up of other causes of acute febrile illness with clinically suspected cases of Leptospirosis. A seroprevalence rate of $>55 \%$ was observed among the general population of North Andamans.

The mortality rate during post flood epidemic of Leptospirosis in Ernakulam district in Kerala was less than 1\%.In 2009, during an outbreak of Leptospirosis in Philippines after floods the mortality rate reported was $10.8 \%$.It was much higher than the mortality rate reported in Kerala. The significant reduction in mortality rate is due to the involvement of the most effective health care systems. Prevention and control of the infectious disease Leptospirosis was achieved by the awareness programmes, prophylactic antibiotic administration at the primary health centre level and strict adherence to the protocol and guidelines implemented by health care providers of Health services from Government of Kerala.

\section{Conclusion}

Leptospirosis is emerging as an important public health problem in India. Both humans and animals may be directly infected through contact with infected tissue or urine of rats or indirectly through contact with contaminated soil and water. It is an occupational hazard of agricultural workers, sewage workers, animal handlers, forestry workers and men involved in outdoor activities who work in wet conditions, Epidemics associated with high case fatality rate $>15 \%$ occur after heavy rainfall. The public health importance lies in its occupational, seasonal, sex and age related incidence. The climatic conditions in tropical and sub-tropical regions provide optimal environment to support the survival of Leptospira 
and infect human beings and it is a potential hazard to the community.

Leptospirosis has been under-reported in most parts of India due to non-availability of laboratory diagnostic facilities. It is a preventable disease. Timely diagnosis and early antibiotic therapy helps to reduce the mortality rate significantly which was evident in the last post flood epidemic in Kerala.

\section{Acknowledgement}

We gratefully acknowledge the great help offered by Dr.Anukumar, Director, ICMR - National Institute of Virology (Kerala unit), Vandanam, Alappuzha in doing PCR testing during the epidemic of Leptospirosis at Ernakulam district.

We are grateful to Dr. GArun Kumar, Professor and Head, Manipal centre for Virus Research, Manipal Academy of Higher education, Karnataka for his timely help in doing PCR for the samples sent from GMC, Ernakulam during the early phase of the outbreak.

We thank Mr.Anoop from Manipal centre for Virus Research for accepting the samples sent from GMC, Ernakulam and promptly doing PCR in the initial phase.

Our sincere thanks to Mr.Hari, our lab assistant who was doing the perfect packing of the samples sent to NIV, Alappuzha and Mr. Madhu who ws involved in the transportation of samples from GMC, Ernakulam to NIV, Alappuzha.

\section{References}

1. S Mullan et al ,Polymerase Chain Reaction,An important tool for early diagnosis of Leptospirosis cases. Journal of Clinical and Diagnostic Research 2016 Dec,Vol10(12): DC 08-DC11

2. R Kanimozhi et al, A Serological study of Leptospirosis in Chennai, International journal of Research in Medical Sciences.

3. France G Terpan, Outbreak of Leptospirosis during a can yoning weekend, t et al,2017,vol:66 supplement 5,July 2018 Pages S361

4. G Vimala, Mary Josephine Rani, Raja Gopal, Leptospirosis in Vellore :A clinical and Serological study. International Journal of Microbiology Vol 2014 10.1155/2014/643940

5. V Chauhan, Mahesh, Panda et al, Profile of patients of Leptospirosis in Sub Himalayan region of North India. JAPI, June 2010 Vol :58:354-356

6. R. Chaudry, Das, Premlatha et al, Serological and molecular approaches for diagnosis of Leptospirosis in a tertiary care hospital in North India: A 10 year study, Indian Journal of Medical Research,2013 April 137(4):785-790

7. Al-Share, T Amilasan, Mugenvijile et al, Outbreak of Leptospirosis after flood, the Philippines,2009,Emerging Infectious diseases Vol:18,No.1, January 2012 pages 91-93

8. Karande S, Kulkarni H, Kulkarni M et al, Leptospirosis in children in Mumbai slums, Indian Journal of Paediatrics, 2002,69:855-858

9. M Nizamuddin et al, Early diagnosis of human Leptospirosis by Antigen detection in blood.Indian Journal of Medical Microbiology,Oct 2006,Vol 24:No.4

10. Smita B Shekatkar, Belgode $\mathrm{N}$ et al ,Clinical and Serological evaluation of Leptospirosis in Puducherry, India.. Journal of Infection in Developing countries, 2010:4(3):139-143

11. Harrisons Principles of medicine 2008, Vol $1,17^{\text {th }}$ Edition Pages 1048-51. 